Journal of Educational Technology

$\&$ Online Learning

Volume 5 | Issue 1 | 2022

http://dergipark.org.tr/jetol

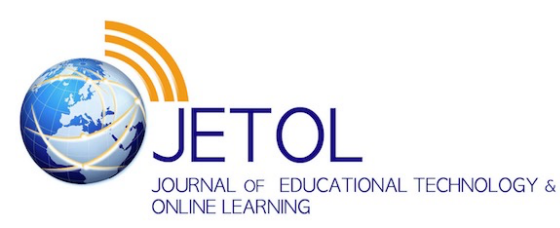

\title{
Book review: Handbook of research on emerging pedagogies for the future of education: Trauma-informed, care, and pandemic pedagogy
}

Sevgi Elibol a *

${ }^{a}$ Anadolu University, Turkey

Suggested citation: Elibol, S. (2022). Book review: Handbook of research on emerging pedagogies for the future of education: Traumainformed, care, and pandemic pedagogy. Journal of Educational Technology \& Online Learning, 5(1), 263-269

\begin{tabular}{|c|c|}
\hline Article Info & Abstract \\
\hline Keywords: & The book entitled Handbook of Research on Emerging Pedagogies for the Future of \\
\hline COVID-19 & Education: Trauma-Informed, Care, and Pandemic Pedagogy, is edited by Aras Bozkurt \\
\hline Emergency remote teaching & 021) from Anadolu University, Turkey. The first edition of the book is published by \\
\hline Trauma-informed pedagogy & IGI Global in 2021. The book has a total of 511 pages and includes two sections (1. \\
\hline Pedagogy of Care & Emergency Remote Teaching and Learning and 2.Trauma-Informed, Care, and \\
\hline Pandemic Pedagogy & $\begin{array}{l}\text { Pandemic Pedagogy) with } 22 \text { chapters covering a wide range of topics. The meta-data of } \\
\text { the book is as followings: DOI: } 10.4018 / 978-1-7998-7275-7 \text {, ISBN13: } 9781799872757 \text {, }\end{array}$ \\
\hline Book Review & $\begin{array}{l}\text { ISBN10: 1799872750, EISBN13: 9781799872771, and ISBN13 Softcover: } \\
\text { 9781799872764. }\end{array}$ \\
\hline
\end{tabular}

\section{Introduction}

The book, Handbook of Research on Emerging Pedagogies for the Future of Education: Trauma-Informed, Care, and Pandemic Pedagogy, is edited by Aras Bozkurt (2021) from Anadolu University, Turkey. The first edition of the book is published by IGI Global in 2021. The book has a total of 511 pages and includes two sections (1. Emergency Remote Teaching and Learning and 2. Trauma-Informed, Care, and Pandemic Pedagogy) with 22 chapters covering a wide range of topics. The meta-data of the book is as followings: DOI: 10.4018/978-1-7998-7275-7, ISBN13: 9781799872757, ISBN10: 1799872750, EISBN13: 9781799872771, and ISBN13 Softcover: 9781799872764.

The world, globally, was hit by the Coronavirus (COVID-19) pandemic and it affected all dimensions of our lives, including education. As a response, emergency remote teaching and learning was implemented to respond to the waves of the pandemic (Bond, 2020; Bozkurt et al., 2020; Bozkurt and Sharma, 2020a; Hodges et al., 2020; Toquero). According to the Horizon Report (EDUCAUSE, 2021), the COVID-19 pandemic pushed education to change and "it isn't hard to imagine that higher education may never be the same in some important ways" (p. 4). The impact and depth of the pandemic required us to reinterpret the world as we know which was referred to be the new normal (Bozkurt \& Sharma, 2020b; Quilter-Pinner, \& Ambrose, 2020). In this regard, the edited book focuses on emergency remote teaching and learning practices and explores important ingredients of these practices which are pedagogy of care, traumainformed pedagogy and pandemic pedagogy.

\footnotetext{
* Corresponding author. Anadolu University, Turkey.

e-mail address: sevgi_sahin@anadolu.edu.tr
} 


\section{Overview of the Book}

The edited book provides a total of 22 chapters. The first chapter, entitled From Equality to Equity to Justice: Should Online Education Be the New Normal in Education?, and written by Xiao (2021), deals with critical issues such as equality, equity, and justice in education from the perspective of post-covid world, that is, the new normal. The author indicates the potential of open education and further argues that the crisis can be turned into an opportunity to heal the already broken educational system.

The second chapter, entitled as Resilient Sustainable Education for the Future of Education: Emerging Challenges by Ossiannilsson (2021), brings unprecedented challenges education have gone and will possibly continue to go through into question and discusses the significance of reshaping the future of education by learning from the past. The author puts an emphasis on improving the social dimensions of learning and education such as social justice, human rights, and democracy in this attempt.

The third chapter, authored by Lelli, Ballard and Gentile (2021), is entitled as Navigating the Barriers Presented by the COVID-19 Pandemic: Reflections and Innovative Educational Solutions. This chapter seeks to address barriers and experiences presented by the sudden change in delivering instruction during COVID-19 in the light of a qualitative study based on COVID-19 Educator Impact Survey. The author also draws our attention to the importance of implementation of Trauma Informed Practices (TIP) for an equitable education and highlights Guideposts for Trauma Informed Strategies which present certain implications for an effective review of pedagogical practices and educational policies that stakeholders should be mindful of.

The fourth chapter, The University Instructors' Opinions About Emergency Remote Education in Turkey, written by Kayaduman and Battal (2021), examines the instructors' positive and negative attitudes towards emergency remote education practices and the underlying reasons as well as their educational preferences and support demands during the COVID-19 pandemic. This chapter also puts forward some implications that hold promise for mitigating the digital divide and digital literacy issues in online education.

The fifth chapter, entitled as Best Practices for Emergency Remote Teaching by Dennis (2021), sheds light on the best practices for online course design, faculty training, and student support to eliminate possible setbacks or the problems already in hand throughout the emergency remote teaching period that serves as a remedy for the academic loss during pandemic. With this in mind, the author also suggests that effective communication strategies must be implemented to ensure cohesion and nurture community within the organization in this chapter.

The sixth chapter, authored by Hamutoglu (2021), is entitled as A Road Map for the COVID-19 Pandemic Process to Ensure Quality of Assurance Active Learning Strategies in Online Learning Environments: How to Plan, Implement, Evaluate, and Improve Learning Activities. This chapter aims to provide guidelines and recommendations for both decision makers and practitioners to plan, implement, evaluate and improve activities in online learning environments during COVID-19. The author proposes an eclectic model called "FlipHyb" as an alternative scenario to be considered while designing online courses and suggests that a well-designed course could help cover learning outcomes thought to be neglected in most scenarios and would definitely ensure the quality.

The seventh chapter, Factors Influencing Student Engagement During COVID-19 Emergency Remote Teaching, written by Ekici (2021), deals with the circumstances affecting student engagement during the emergency remote teaching period caused by the COVID-19 outbreak. The author examines those factors on both personal and institutional level and reveals the significance of taking the right steps to improve student engagement by mentioning the upcoming challenges that are wished to pursue.

The eighth chapter, entitled as An Ethnographic Phenomenology of Pandemic Pedagogy: K12 Teachers' Choices for Student Learning by Rodgers (2021), analyses the best practice-driven pedagogical strategies for online teaching and learning based on the feedback received from K12 teachers' experiences in the COVID-19 process and the ethnographic reflections of an Education Technology Specialist and interpreted 
in the light of Technology Acceptance Model Framework (TAM-2). The author also explores impediments to pandemic pedagogy and strategies for a supervised student engagement.

The ninth chapter, authored by Grant-Smith and Payne (2021), is entitled Enacting Care-Ful Engagement in the (Post)Pandemic Care-Less University. This chapter explores the caring role or responsibility teachers have employed throughout the pandemic to contribute to students' conscious, enduring and care-ful engagement by means of presenting a student engagement model based on an autoethnographic reflection of emergency remote teaching.

The tenth chapter, Opinions of Field Experts on Practices That Will Increase the Motivation Levels of Learners During the COVID-19 Pandemic Process, written by K1lınç (2021), explores the ways to enhance motivation levels of learners during the COVID-19 pandemic process and the roles that teachers, institutions, families, and learners should adopt to sustain their motivation in this process.

The eleventh chapter, entitled as Determination of Preschool Teacher Candidates' Views on the Learning Management System Used in the COVID-19 Pandemic Process by Altinpulluk (2021), deals with learning management systems (LMS) in the COVID-19 pandemic process in Turkey according to through the lens of preschool teacher candidates. In this chapter, based on the analysis of live lectures, discussion forums, and assignments/online exams tools in the LMS, the general usability of the LMS is discussed and implications for an effective implementation of LMS are presented.

The twelfth chapter, authored by Kesim (2021) is entitled The Impact of the COVID-19 Pandemic on the Field of Economics of Education: An Analysis Based on Digital Skills. This chapter focuses on the economic dimension of distance education which is considered vital in terms of its social consequences. Throughout the chapter, the effects of the pandemic on educational institutions, the significance of employing digital skills in global competition and the paradigm shifts in educational economy are discussed and evaluated.

The thirteenth chapter, An Analysis of Fully Synchronous Pandemic Secondary Education, written by Ryan (2021), focuses on strengths and shortcomings of an entirely synchronous learning experience for secondary students by providing precious recommendations for the future of such areas as general education, special education, and English language teaching through distance learning. The chapter also reveals some strategies to engage, assess and support secondary students as well as curriculum and course design ideas for teachers.

The fourteenth chapter, entitled as Good Vibes Only: Learning English at a Distance Within Pandemic Pedagogy by Goksel (2021), focuses on the definitions of online solutions and attempts in "emergency remote education" context and different perspectives of pandemic pedagogy during COVID-19 in the world and specifically in Turkey. Through a positive lens the author puts emphasis on the experience of learners enhanced by empathy rather than delivering the instructional content.

The fifteenth chapter, authored by Altunçekiç (2021), is entitled as University Instructors' Views on Distance Medical Education Activities. This chapter investigates the experiences of instructors from different universities regarding practical training, communication, feedback, and classroom management in distance medical education-an area which mainly requires hands-on experience. Alongside the pitfalls, this chapter also presents instructors' appreciations of promising features of distance learning such as accessibility and individual learning.

The sixteenth chapter, Implementation Example for the Structured Mathematics Teaching in Learning Environments During the Pandemic Period, written by Ünveren Bilgiç (2021), aims to provide an exemplary study which would assist academicians and field experts conducting distance education during the COVID-19. The study makes great contributions to a deeper understanding of the basic distinctions between designing face-to-face teaching environments and Emergency remote teaching environments and offers effective implications for an effective implementation of technology into remote teaching environments in the field of mathematics. 
The seventeenth chapter, entitled as Intolerance of Uncertainty Experienced by Faculty of Education Students in the COVID-19 Pandemic and Their Strategies to Cope with Uncertainty by Alkış Küçükaydın (2021), aims to examine the intolerance of uncertainty levels of Turkish students during COVID-19 by means of the Intolerance of Uncertainty Scale and the strategies they have pursued to cope with this situation. This chapter also puts forward critical measures to take before inexperienced learners develop a negative attitude because of the difficulty they face in overcoming uncertainty in such processes.

The eighteenth chapter, Pedagogy of the Pandemic: Reflections of Mother-Scholar-Practitioners, written by Falk and Orbon (2021), aims to share certain experiences with emergency remote teaching and learning through a feminist lens and emphasizes the need for a content-rich curriculum and a supportive environment which involves putting students and families at the center for an effective execution of emergency remote teaching.

The nineteenth chapter, authored by Taskiran is entitled as Psycho-Social Well-Being of Young Learners During Emergency Remote Teaching: General Scope and Suggestions for Improvement. This chapter explores psycho-social well-being of K-12 level learners which deserves no less attention than financial, sociological, and psychological consequences of COVID-19 pandemic and explains the significance of considering psychosocial well-being of the young as an indispensable component while designing remote teaching.

The twentieth chapter, entitled as Empowering Teachers Who Work in Inclusive Practices: E-Coaching by Uysal, Sani-Bozkurt, Bozkus-Genc and Gurgur (2021), deals with the new competencies teachers are expected to employ as a result of the suspension of face-to-face education during COVID-19 pandemic. The authors propose an e-coaching approach, which is free of time, space and form boundaries, as an alternative approach for educators to overcome the current obstacles as well as possible ones to be faced in the long term.

The twenty-first chapter, Play Specialist-Based Intervention in the COVID-19 Era: Crisis and Opportunities of Change - An Experience From Italy, written by Perasso, Boldrini, Maggiore, Allegri and Camurati (2021), focuses on structured play programs and the importance of their integration into telematic environments by teachers, educators, experts in pedagogy, psychologists, pediatricians, and parents of children with medical conditions to overcome the obstacles given by pandemic emergency and social isolation.

The twenty-second chapter, authored by Charamba (2021) is entitled The Power of Inclusion: Embracing Multilingual E-Learning Opportunities in Science Education. This chapter explores the pivotal role of the language in the e-learning lessons conducted through videos, multilingual glossaries, and narrated slides of multilingual science students at a secondary school in South Africa. The author also puts forward great suggestions about the cognitive and socio-cultural contributions of multilingual e-learning pedagogy to education.

\section{Conclusion and Suggestions}

The edited book is highly relevant considering the crisis due to coronavirus pandemic. The pandemic led to trauma, anxiety, and stress (Talidong \& Toquero, 2020) and this requires prioritizing pandemic pedagogy (Bozkurt \& Sharma, 2021) as learning is social and social dimension of learning should focus on how to humanize teaching and learning (Baran, E., \& AlZoubi, 2020). It is for sure that COVID-19 will require us to redesign the education by focusing on lessons learned by the implementation of emergency remote teaching and learning and by the need for trauma-informed, care, and pandemic pedagogy. In line with these perspectives, the chapters covering various issues can be a guide base for those who want to explore these issues. As outlined in the chapters, these issues can include pedagogical implications which were hammered by care and empathy in the emergency situations as in the COVID-19 crisis. 


\section{References}

Alkış Küçükaydın, M. (2021). Intolerance of Uncertainty Experienced by Faculty of Education Students in the COVID-19 Pandemic and Their Strategies to Cope with Uncertainty. In Bozkurt, A. (Eds.), Handbook of Research on Emerging Pedagogies for the Future of Education: Trauma-Informed, Care, and Pandemic Pedagogy (pp. 328-346). IGI Global. http://doi:10.4018/978-1-7998-72757.ch017

Altinpulluk, H. (2021). Determination of Preschool Teacher Candidates' Views on the Learning Management System Used in the COVID-19 Pandemic Process. In Bozkurt, A. (Eds.), Handbook of Research on Emerging Pedagogies for the Future of Education: Trauma-Informed, Care, and Pandemic Pedagogy (pp. 209-229). IGI Global. http://doi:10.4018/978-1-7998-7275-7.ch011

Altunçekiç, A. (2021). University instructors' views on distance medical education activities. In Bozkurt, A. (Eds.), Handbook of Research on Emerging Pedagogies for the Future of Education: TraumaInformed, Care, and Pandemic Pedagogy (pp. 284-300). IGI Global. http://doi:10.4018/978-1$\underline{7998-7275-7 . \operatorname{ch} 015}$

Baran, E., \& AlZoubi, D. (2020). Human-centered design as a frame for transition to remote teaching during the COVID-19 pandemic. Journal of Technology and Teacher Education, 28(2), 365-372. https://www.learntechlib.org/p/216077/

Bond, M. (2020). Schools and emergency remote education during the COVID-19 pandemic: A living rapid systematic review. Asian Journal of Distance Education, 15(2), 191- 247. http://www.asianjde.org/ojs/index.php/AsianJDE/article/view/517

Bozkurt, A. (2021). Handbook of Research on Emerging Pedagogies for the Future of Education: TraumaInformed, Care, and Pandemic Pedagogy. IGI Global. http://doi:10.4018/978-1-7998-7275-7

Bozkurt, A., \& Sharma, R. C. (2020a). Emergency remote teaching in a time of global crisis due to CoronaVirus pandemic. Asian Journal of Distance Education, 15(1), i-vi. https://doi.org/10.5281/zenodo.3778083

Bozkurt, A., \& Sharma, R. C. (2020b). Education in normal, new normal, and next normal: Observations from the past, insights from the present and projections for the future. Asian Journal of Distance Education, 15(2), i-x. https://doi.org/10.5281/zenodo.4362664

Bozkurt, A., \& Sharma, R. C. (2021). On the verge of a new renaissance: Care and empathy oriented, human-centered pandemic pedagogy. Asian Journal of Distance Education, 16(1), i-vii. https://doi.org/10.5281/zenodo.5070496

Bozkurt, A., Jung, I., Xiao, J., Vladimirschi, V., Schuwer, R., Egorov, G., .. \& Paskevicius, M. (2020). A global outlook to the interruption of education due to COVID-19 pandemic: Navigating in a time of uncertainty and crisis. Asian Journal of Distance Education, 15(1), 1-126. https://doi.org/10.5281/zenodo.3878572

Charamba, E. (2021). The power of inclusion: Embracing multilingual e-learning opportunities in science education. In Bozkurt, A. (Eds.), Handbook of Research on Emerging Pedagogies for the Future of Education: Trauma-Informed, Care, and Pandemic Pedagogy (pp. 421-438). IGI Global. http://doi:10.4018/978-1-7998-7275-7.ch022

Dennis, M. (2021). Best practices for emergency remote teaching. In Bozkurt, A. (Eds.), Handbook of Research on Emerging Pedagogies for the Future of Education: Trauma-Informed, Care, and Pandemic Pedagogy (pp. 82-100). IGI Global. http://doi:10.4018/978-1-7998-7275-7.ch005

EDUCAUSE. (2021). 2021 EDUCAUSE Horizon Report Teaching and Learning Edition. EDUCAUSE. https://library.educause.edu/resources/2021/4/2021-educause-horizon-report-teaching-andlearning-edition 
Ekici, M., \& Inel Ekici, D. (2021). Factors influencing student engagement during COVID-19 emergency remote teaching. In Bozkurt, A. (Ed.), Handbook of Research on Emerging Pedagogies for the Future of Education: Trauma-Informed, Care, and Pandemic Pedagogy (pp. 127-144). IGI Global. http://doi:10.4018/978-1-7998-7275-7.ch007

Falk, A. F., \& Orbon, K. (2021). Pedagogy of the pandemic: Reflections of mother-scholar-practitioners. In Bozkurt, A. (Ed.), Handbook of Research on Emerging Pedagogies for the Future of Education: Trauma-Informed, Care, and Pandemic Pedagogy (pp. 347-367). IGI Global. http://doi:10.4018/978-1-7998-7275-7.ch018

Goksel, N. (2021). Good vibes only: Learning English at a distance within pandemic pedagogy. In Bozkurt, A. (Eds.), Handbook of Research on Emerging Pedagogies for the Future of Education: TraumaInformed, Care, and Pandemic Pedagogy (pp. 269-283). IGI Global. http://doi:10.4018/978-17998-7275-7.ch014

Grant-Smith, D., \& Payne, R. (2021). Enacting care-ful engagement in the (post)pandemic care-less university. In Bozkurt, A. (Ed.), Handbook of Research on Emerging Pedagogies for the Future of Education: Trauma-Informed, Care, and Pandemic Pedagogy (pp. 169-190). IGI Global. http://doi:10.4018/978-1-7998-7275-7.ch009

Hamutoglu, N. B. (2021). A road map for the COVID-19 pandemic process to ensure quality of assurance active learning strategies in online learning environments: How to plan, implement, evaluate, and improve learning activities. In Bozkurt, A. (Eds.), Handbook of Research on Emerging Pedagogies for the Future of Education: Trauma-Informed, Care, and Pandemic Pedagogy (pp. 101-126). IGI Global. http://doi:10.4018/978-1-7998-7275-7.ch006

Hodges, C., Moore, S., Lockee, B., Trust, T., \& Bond, A. (2020). The difference between emergency remote teaching and online learning. Educause Review. Available at https://er.educause.edu/articles/2020/3/the-difference-between-emergency-remote-teaching-andonline-learning

Kayaduman, H., \& Battal, A. (2021). The university instructors' opinions about emergency remote education in Turkey. In Bozkurt, A. (Ed.), Handbook of Research on Emerging Pedagogies for the Future of Education: Trauma-Informed, Care, and Pandemic Pedagogy (pp. 66-81). IGI Global. http://doi:10.4018/978-1-7998-7275-7.ch004

Kesim, E. (2021). the impact of the COVID-19 pandemic on the field of economics of education: an analysis based on digital skills. In Bozkurt, A. (Eds.), Handbook of Research on Emerging Pedagogies for the Future of Education: Trauma-Informed, Care, and Pandemic Pedagogy (pp. 230-249). IGI Global. http://doi:10.4018/978-1-7998-7275-7.ch012

Kılınç, H. (2021). Opinions of field experts on practices that will increase the motivation levels of learners during the COVID-19 pandemic process. In Bozkurt, A. (Eds.), Handbook of Research on Emerging Pedagogies for the Future of Education: Trauma-Informed, Care, and Pandemic Pedagogy (pp. 191-208). IGI Global. http://doi:10.4018/978-1-7998-7275-7.ch010

Lelli, C., Ballard, K. M., \& Gentile, A. (2021). Navigating the barriers presented by the COVID-19 pandemic: reflections and innovative educational solutions. In Bozkurt, A. (Ed.), Handbook of Research on Emerging Pedagogies for the Future of Education: Trauma-Informed, Care, and Pandemic Pedagogy (pp. 44-65). IGI Global. http://doi:10.4018/978-1-7998-7275-7.ch003

Ossiannilsson, E. S. (2021). Resilient sustainable education for the future of education: Emerging challenges. In Bozkurt, A. (Eds.), Handbook of Research on Emerging Pedagogies for the Future of Education: Trauma-Informed, Care, and Pandemic Pedagogy (pp. 16-43). IGI Global. http://doi:10.4018/978-1-7998-7275-7.ch002 
Perasso, G., Boldrini, G., Maggiore, A., Allegri, C., \& Camurati, G. (2021). Play specialist-based intervention in the COVID-19 era: crisis and opportunities of change - an experience from Italy. In Bozkurt, A. (Ed.), Handbook of Research on Emerging Pedagogies for the Future of Education: Trauma-Informed, Care, and Pandemic Pedagogy (pp. 401-420). IGI Global. http://doi:10.4018/978-1-7998-7275-7.ch021

Quilter-Pinner, H., \& Ambrose, A. (2020). The 'new normal': The future of education after Covid-19. IPPR. http://www.ippr.org/research/publications/the-new-normal

Rodgers, D. J. (2021). An ethnographic phenomenology of pandemic pedagogy: K12 teachers' choices for student learning. In Bozkurt, A. (Eds.), Handbook of Research on Emerging Pedagogies for the Future of Education: Trauma-Informed, Care, and Pandemic Pedagogy (pp. 145-168). IGI Global. http://doi:10.4018/978-1-7998-7275-7.ch008

Ryan, M. P. (2021). An analysis of fully synchronous pandemic secondary education. In Bozkurt, A. (Eds.), Handbook of Research on Emerging Pedagogies for the Future of Education: Trauma-Informed, Care, and Pandemic Pedagogy (pp. 250-268). IGI Global. http://doi:10.4018/978-1-7998-72757.ch013

Talidong, K. J. B., \& Toquero, C. M. D. (2020). Philippine teachers' practices to deal with anxiety amid COVID-19. Journal of Loss and Trauma, 25(6-7), 573-579. https://doi.org/10.1080/15325024.2020.1759225

Taskiran, A. (2021). Psycho-social well-being of young learners during emergency remote teaching: General scope and suggestions for improvement. In Bozkurt, A. (Eds.), Handbook of Research on Emerging Pedagogies for the Future of Education: Trauma-Informed, Care, and Pandemic Pedagogy (pp. 368-385). IGI Global. http://doi:10.4018/978-1-7998-7275-7.ch019

Toquero, C. M. (2020). Emergency remote teaching amid COVID-19: the turning point. Asian Journal of Distance Education, 15(1), 185-188. https://doi.org/10.5281/zenodo.3881748

Ünveren Bilgiç, E. N. (2021). Implementation example for the structured mathematics teaching in learning environments during the pandemic period. In Bozkurt, A. (Eds.), Handbook of Research on Emerging Pedagogies for the Future of Education: Trauma-Informed, Care, and Pandemic Pedagogy (pp. 301-326). IGI Global. http://doi:10.4018/978-1-7998-7275-7.ch016

Uysal, C., Sani-Bozkurt, S., Bozkus-Genc, G., \& Gurgur, H. (2021). Empowering teachers who work in inclusive practices: E-coaching. In Bozkurt, A. (Ed.), Handbook of Research on Emerging Pedagogies for the Future of Education: Trauma-Informed, Care, and Pandemic Pedagogy (pp. 386-400). IGI Global. http://doi:10.4018/978-1-7998-7275-7.ch020

Xiao, J. (2021). From equality to equity to justice: Should online education be the new normal in education?. In Bozkurt, A. (Eds.), Handbook of Research on Emerging Pedagogies for the Future of Education: Trauma-Informed, Care, and Pandemic Pedagogy (pp. 1-15). IGI Global. http://doi:10.4018/9781-7998-7275-7.ch001 